OPEN

SUBJECT AREAS: STRUCTURAL PROPERTIES

METEORITICS

Received

23 December 2013

Accepted

11 February 2014

Published

5 March 2014

Correspondence and requests for materials should be addressed to

D.A.P. (Pavlov@unn.

ru)

\title{
Self-assembled nanocrystals discovered in Chelyabinsk meteorite
}

\author{
D. A. Pavlov, A. I. Bobrov, N. V. Malekhonova, A. V. Pirogov \& A. V. Nezhdanov
}

Department of Semiconductor Physics and Optoelectronics, Faculty of Physics, Lobachevsky State University of Nizhni Novgorod, Prospekt Gagarina 23, Nizhni Novgorod 603950, Russia.

Current interest in nanomaterials is focused mostly on artificial materials fabricated for various applications. However, naturally occurring nanocrystal arrays, like those recently found in the meteorite that fell near Chelyabinsk in Russia on 15 February, 2013, can provide some new insights into the nature of nanomaterials, including the conditions for their natural occurrence. Here we report the results of our spectroscopic investigation of a fragment of the Chelyabinsk meteorite. The atomic structure of a fragment of the Chelyabinsk meteorite was studied using high-resolution transmission electron microscopy. Elemental and phase analysis of the object that was carried out by energy dispersive X-ray spectroscopy and electron diffraction revealed the presence of crystalline phases of different chemical compounds specific to meteorites of the LL group. In addition to single-crystal inclusions, extensive areas with ferropericlase nanocrystals having characteristic sizes from 3 to $15 \mathrm{~nm}$ were found in the structure of the meteorite. The study of the meteorite employing combination scattering of light (Raman) and photoluminescence spectroscopy methods has revealed quantum effects of ferropericlase nanoparticles and related photoluminescence with a maximum in the range of 675-800 $\mathrm{nm}$.

\footnotetext{
( urrently, the attention of many research groups around the world is focused on the problems related to fabrication of various types of nanostructured materials. This is due to the fact that such materials exhibit physical properties that are often vastly different from those of bulk monocrystals having the same chemical composition ${ }^{1}$.

Modern methods for preparation of nanostructured materials rely on creating artificial non-equilibrium conditions that lead to changes in the source material structure ${ }^{1}$. In a similar manner, one can describe the conditions that affected the Chelyabinsk meteorite as it was falling to Earth: an extremely rapid heating in the atmosphere at high pressure, explosion and rapid cooling in the ice of Lake Chebarkul. Our study performed using high-resolution transmission electron microscopy (HR TEM) reveals the formation of extensive areas, which are clusters of nanocrystals in an amorphous matrix, in the structure of the meteorite fragment. This work also demonstrates that the material of the meteorite exhibits luminescence in the wavelength range 675-850 $\mathrm{nm}$.

It should be recalled that the object of our studies was a fragment of the meteorite named after the place of its fall near Chelyabinsk on February 15, 2013. The space body exploded in an air burst at an altitude of $23.3 \mathrm{~km}, 32.5$ seconds after entering the Earth's atmosphere, resulting in many small meteorite fragments landing on the ground $^{2}$. The maximum temperature the object reached during its passage through the Earth's atmosphere was estimated at about $10^{4} \mathrm{~K}^{3}$. Figure 1 shows the photograph of one of such fragments studied in this work.
}

\section{Results}

The first stage of the research involved an overall analysis of the elemental composition of the object using energydispersive X-ray spectroscopy to confirm the meteorite nature of its origin. Our results are very similar to the results concerning the chemical content of many other meteorites [see for example 4, 5, 6].

It should be noted that local composition of the samples as measured by energy dispersive spectroscopy (EDS) is rather non-uniform, and the ratio of elements varies greatly depending on the location at which the measurements are made. However, the main list of the chemical elements is the same for all the measurements made in the study of this object, and is in good agreement with the data of similar earlier research of meteorites [articles 3 and 4 on the composition of meteorites]. Thus, Fig. 2 shows an overview picture of the core structure of the meteorite sample obtained in the scanning transmission electron microscope mode (STEM) and the corresponding element distribution maps. The table under a group of pictures shows the general chemical composition of the corresponding region of the meteorite (Fig. 2). 


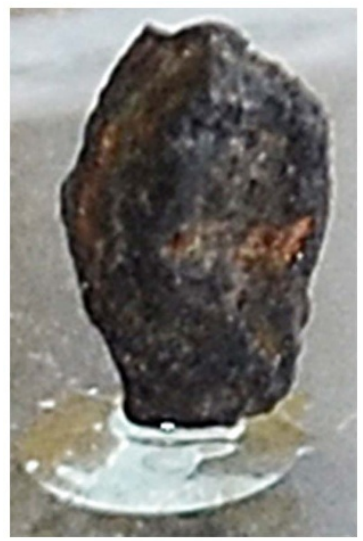

Figure $1 \mid$ Meteorite fragment. The photograph was taken by A. Pirogov.

As follows from the distribution maps of chemical elements, the central light-contrast area of the image obtained by scanning transmission electron microscopy corresponds to aluminosilicate glass. Inclusions having extremely dark contrast are FeS (troilite) or $(\mathrm{Ni}$, $\mathrm{Fe})_{3} \mathrm{~S}_{2}$ (heazlewoodite) compounds. Intermediate contrast corresponds to olivine $(\mathrm{Mg}, \mathrm{Fe})_{2}\left[\mathrm{SiO}_{4}\right]$ and diopside $(\mathrm{CaMg})\left[\mathrm{Si}_{2} \mathrm{O}_{6}\right]$, performing the role of the matrix. These results are consistent with previously published data on the structure of meteorites obtained by transmission electron microscopy ${ }^{4}$.

Further research was focused on the study of the meteorite using high-resolution transmission electron microscopy. As a result, it was found that the structure of inclusions with elemental composition
Table 1 The results of the indexing of electron diffraction patterns of the crystalline olivine and comparison with previously published data from ${ }^{7}$

\begin{tabular}{lccc} 
Olivine & $\begin{array}{c}\text { The system } \\
\text { of planes }\end{array}$ & $\begin{array}{c}\text { Lattice parameters } \\
\text { according to } \\
\text { [7] d, } \AA\end{array}$ & $\begin{array}{c}\text { Results of } \\
\text { electronograms } \\
\text { d, } \AA\end{array}$ \\
\hline$\left(\mathrm{Mg}_{1.4} \mathrm{Fe}_{0.6}\right) \mathrm{SiO}_{4}$ & $(01-1)$ & 5.19 & $5.15 \pm 0.14$ \\
& $(111)$ & 3.52 & $3.48 \pm 0.09$ \\
& $(0-22)$ & 2.6 & $2.48 \pm 0.07$ \\
& $(1-13)$ & 1.86 & $1.93 \pm 0.06$ \\
\hline
\end{tabular}

corresponding to the mineral olivine was substantially non-uniform. Areas of crystalline olivine were easily identified by the electron diffraction (Table 1). In addition to single-crystal grains of olivine, extensive areas were revealed that were filled with nanocrystals ranging in size from 3 to $15 \mathrm{~nm}$ in an amorphous matrix (Fig. 3). Figure 4 shows the boundary between the crystalline olivine (location 1) and the nanostructured area (location 2).

From the electron-diffraction data, interplanar spacings were established, which characterize the material of nanocrystals. These results are shown in Table 2 . The only material that matches the crystal lattice parameters and at the same time corresponds to the elemental composition in nanostructured areas is ferropericlase $(\mathrm{Mg}, \mathrm{Fe}) \mathrm{O}$. Judging from the stoichiometric ratio of elements determined by energy dispersive X-ray spectroscopy (Table 3), we can conclude that the matrix for nanocrystals is provided by amorphous silica $\left(\mathrm{SiO}_{2}\right)$.
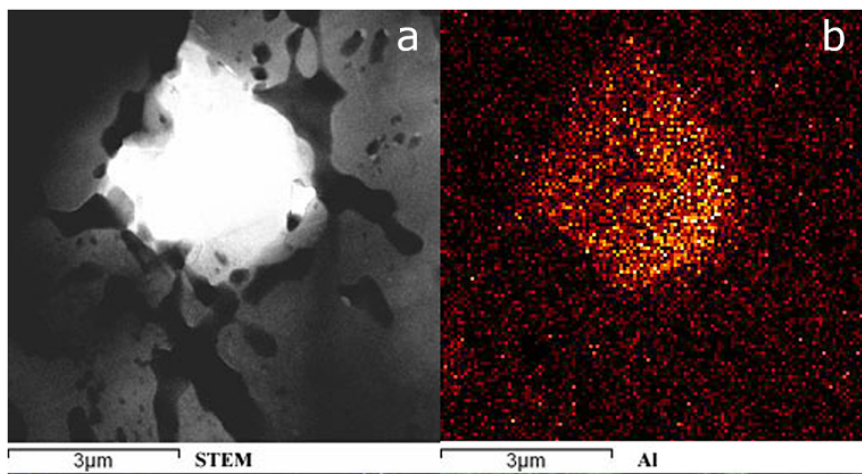

b
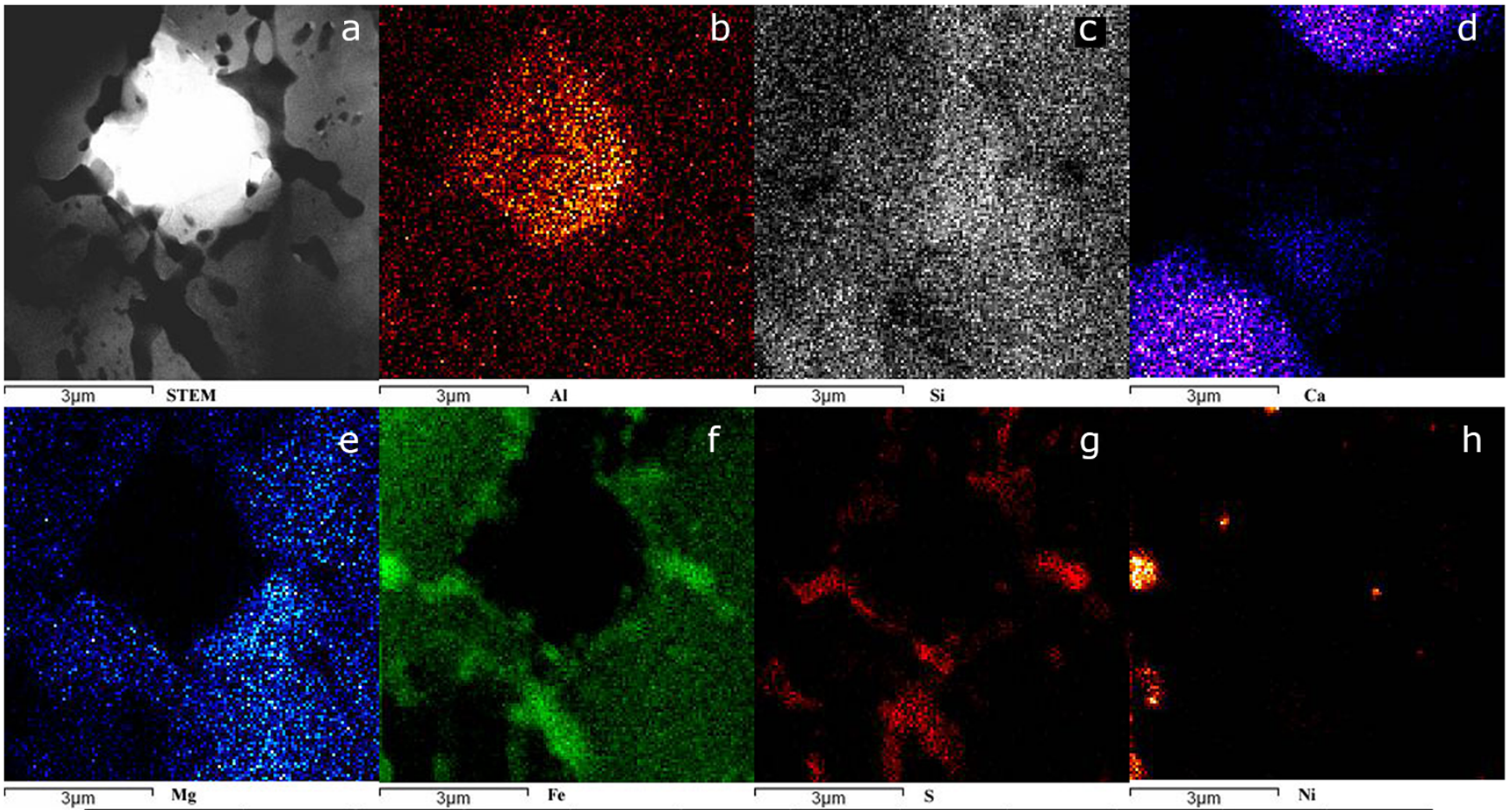

$3 \mu \mathrm{m}$ Al
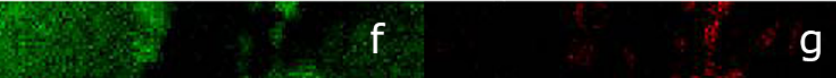

\begin{tabular}{|c|c|c|c|c|c|c|c|c|c|c|c|}
\hline Element & $\mathrm{O}$ & $\mathrm{Si}$ & $\mathrm{Fe}$ & $\mathrm{Ca}$ & $\mathrm{Mg}$ & $\mathrm{Cu}$ & $\mathrm{S}$ & $\mathrm{Al}$ & $\mathrm{Zn}$ & $\mathrm{Ni}$ & $\mathrm{Mn}$ \\
\hline At.\% & 33.7 & 20.5 & 16.1 & 10.4 & 8.5 & 3.7 & 3.4 & 1.3 & 1.3 & 0.3 & 0.2 \\
\hline
\end{tabular}

Figure $2 \mid$ (a) STEM image of the area containing micron-size inclusions of various phases. (b-h) element distribution maps. Below the image, a table presents the averaged results of the analysis of the meteorite chemical composition. 


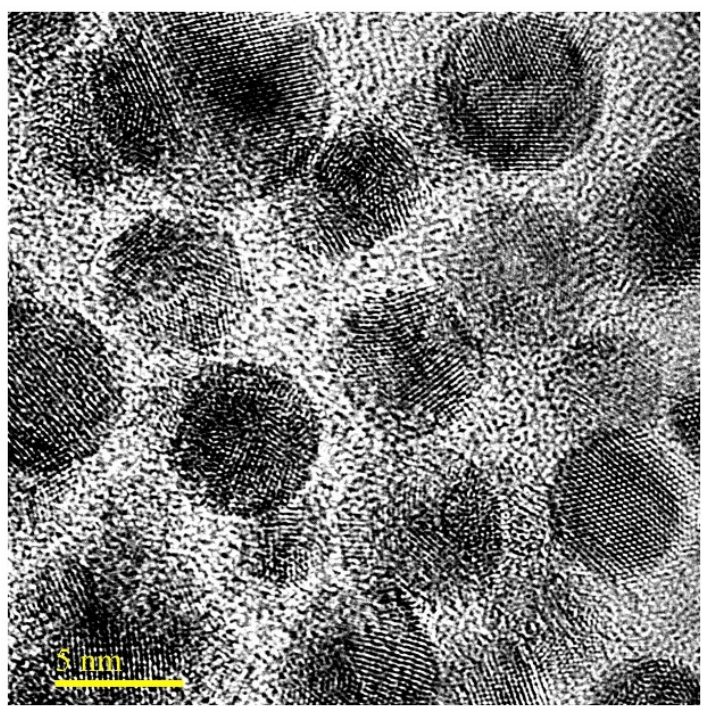

Figure 3 | Nanocrystal array (atomic resolution).

The optical properties of the sample at its cross-section were investigated by confocal microscopy combined with Raman and photoluminescence spectroscopy. Figure 5 shows an image of the meteorite cross-section taken using Raman spectroscopy.

One can also see considerable heterogeneity of the sample structure, the presence of many different inclusions of micron sizes with rather sharp boundaries between them. Several characteristic spectra detected during the experiment were analyzed and compared with the reference data of the RRUFF ${ }^{\mathrm{TM}}$ database. As a result, we established, with the probability of over 80 percent, the presence of the following chemical compounds in the structure of the meteorite: $\mathrm{Mg}_{2} \mathrm{SiO}_{4}$ (forsterite), $\mathrm{CaMgSi}_{2} \mathrm{O}_{6}$ (diopside), $\mathrm{Si}$ (silicon crystal), $\mathrm{FeS}$ (troilite), $\mathrm{CaAl}_{2} \mathrm{Si}_{2} \mathrm{O}_{8}$ (anorthite) (Fig. 5).

Our studies of the same region in the scan mode of PL spectroscopy have revealed the presence of a broad and intense photoluminescence peak in the range of 650-850 $\mathrm{nm}$. The distribution map of photoluminescence is shown in Figure 6. When comparing this map with the maps of Raman spectroscopy, we found that luminescence is only confined to the areas with diopside $\left(\mathrm{CaMgSi}_{2} \mathrm{O}_{6}\right)$. To establish the possible causes of this effect, we re-examined the respective areas using a transmission electron microscope. As a result, some areas with nanocrystals were discovered in diopside $\left(\mathrm{CaMgSi}_{2} \mathrm{O}_{6}\right)$ inclusions. These nanocrystals had the same interplanar distances as the nanocrystals detected in olivine (Table 3 ).

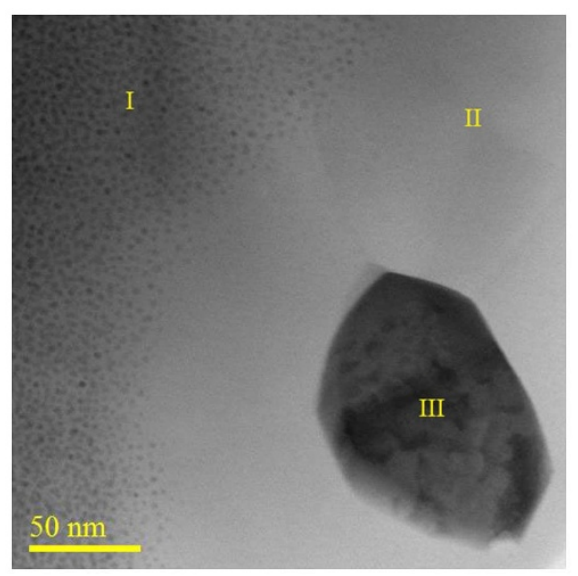

Figure $4 \mid$ The boundary between the nanostructured area (I) and the crystalline olivine (II). Location III is the inclusion of troilite (FeS).
Table 2 | The results of the indexing of electron diffraction patterns of nanocrystals of ferropericlase and comparison with previously published data from ${ }^{8}$

\begin{tabular}{lccc} 
Ferropericlase & $\begin{array}{c}\text { The system } \\
\text { of planes }\end{array}$ & $\begin{array}{c}\text { Lattice parameters } \\
\text { according to } \\
{[8] \mathrm{d}, \AA}\end{array}$ & $\begin{array}{c}\text { Results of } \\
\text { electronograms } \\
\mathrm{d}, \AA\end{array}$ \\
\hline$\left(\mathrm{Mg}_{0.8} \mathrm{Fe}_{0.2)} \mathrm{O}\right.$ & $(1-11)$ & 2.32 & $2.23 \pm 0.11$ \\
& $(002)$ & 2.01 & $2.01 \pm 0.12$ \\
& $(2-20)$ & 1.43 & $1.36 \pm 0.06$ \\
& $(1-13)$ & 1.22 & $1.18 \pm 0.05$ \\
\hline
\end{tabular}

\section{Discussion}

Thus, following the standard classification ${ }^{5,6}$, this meteorite can be classified as a LL ordinary chondrite.

The chemical composition of olivine and the areas with nanocrystals is almost identical. The only difference revealed in the elemental composition of these two phases is the presence of small impurities of copper and zinc ( $1.2 \pm 0.3$ and $0.5 \pm 0.1$ at.\% respectively) in the area with nanocrystals (Table 3 ). It can be assumed that namely these elements, combined with the nonequilibrium conditions that affected the meteorite after it entered the Earth atmosphere, have played a catalytic role in the formation of nanocrystals.

At this moment, it is not possible to present any direct evidence that photoluminescence is associated with nanocrystals. However, the existence of such an association is implied by the considerable spectrum width and by the absence of pronounced maxima, which is characteristic of quantum-dimensional nature of photoluminescence. If we adopt this hypothesis, the widening of the PL spectrum may be easily explained by the spread in nanocrystal sizes.

In any case, the very fact that nanocrystals were found in a meteorite is undoubtedly of interest and deserves discussion among the research community. Further research in this area can prove valuable.

\section{Methods}

To investigate the structure and chemical composition of the meteorite, we used a JEM-2100F transmission electron microscope (TEM) (JEOL, Japan). Elemental analysis was performed using a X-Max energy dispersive X-ray detector (Oxford instruments, UK) mounted on the transmission electron microscope. The object of the study was the core of the meteorite fragment. The specimen for TEM was prepared by standard techniques using Gatan-691 Precision Ion Polishing System. Ion energies from 5 to $2 \mathrm{keV}$ and the beam angles from $-7^{\circ}$ to $3^{\circ}$ were used at the final stage of precision ion etching. Heat removal during etching was ensured by the reliable fastening of the sample. The estimation shows that the temperature during etching does not exceed $100-150^{\circ} \mathrm{C}$.

The studies of combination scattering of light (CSL) and photoluminescence (PL) spectra of the meteorite sample were carried out using the reflective mode of the scanning confocal Raman/fluorescence microscope NTEGRA Spectra produced by NT-MDT (Zelenograd). A semiconductor laser with a wavelength of $473 \mathrm{~nm}$ and beam power $\sim 5 \mathrm{~mW}$ was used for the measurement. The laser beam was focused using a $100 \times$ lens with an aperture of $\mathrm{NA}=0,95$. All spectra were measured at room temperature. The Raman study was carried out in the range of $150-1600 \mathrm{~cm}^{-1}$. Photoluminescence spectra were measured in the range of 500-850 $\mathrm{nm}$.

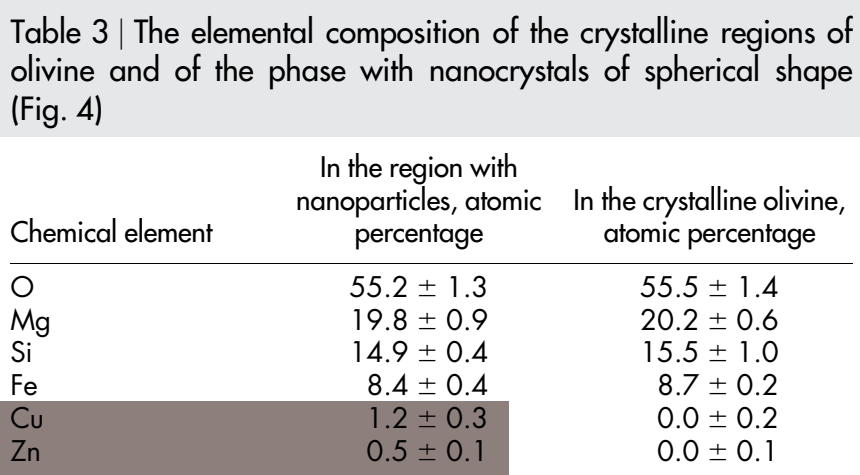



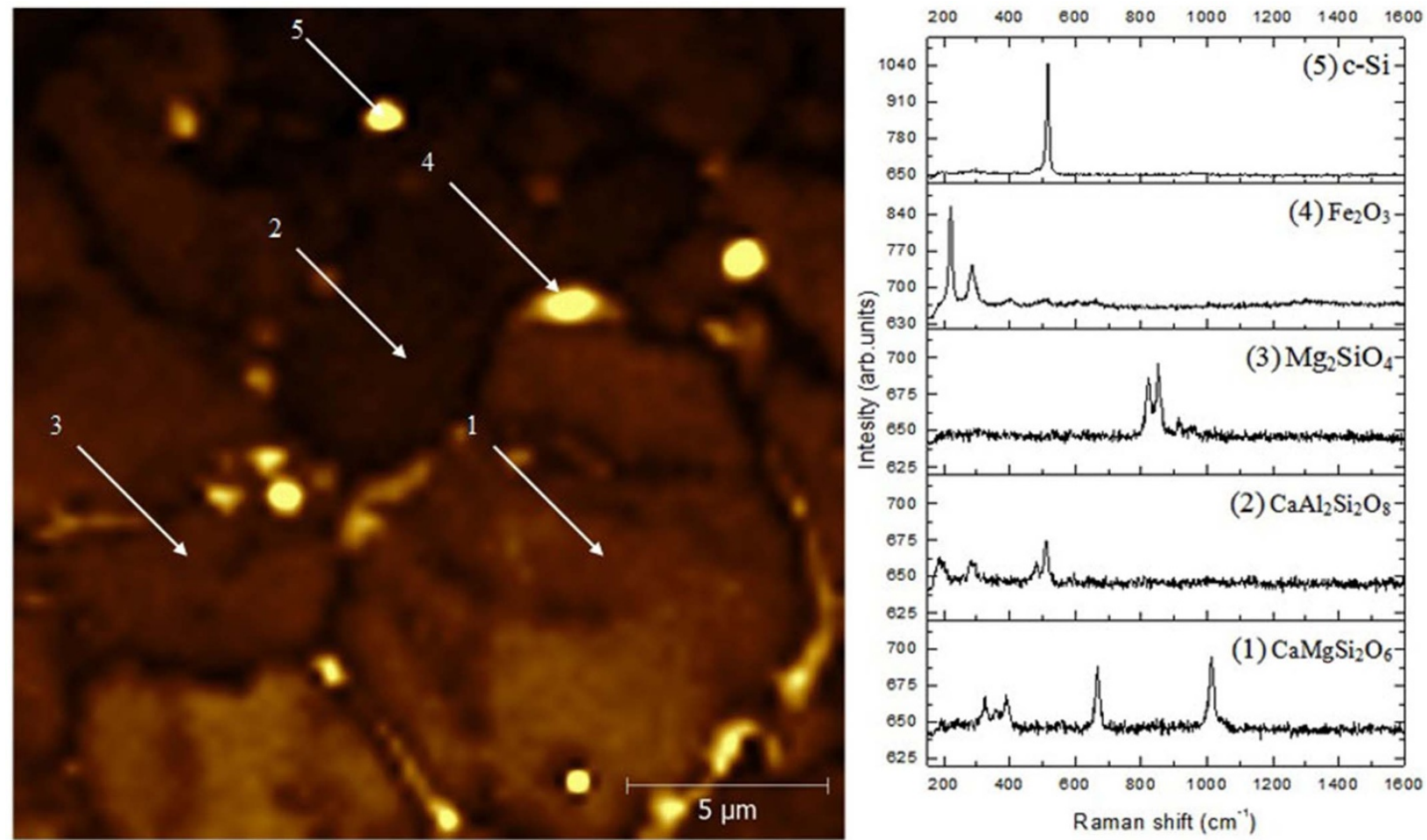

Figure $5 \mid$ The image of the sample in the confocal microscope mode and the spectra of Raman scattering corresponding to the areas marked in the image.

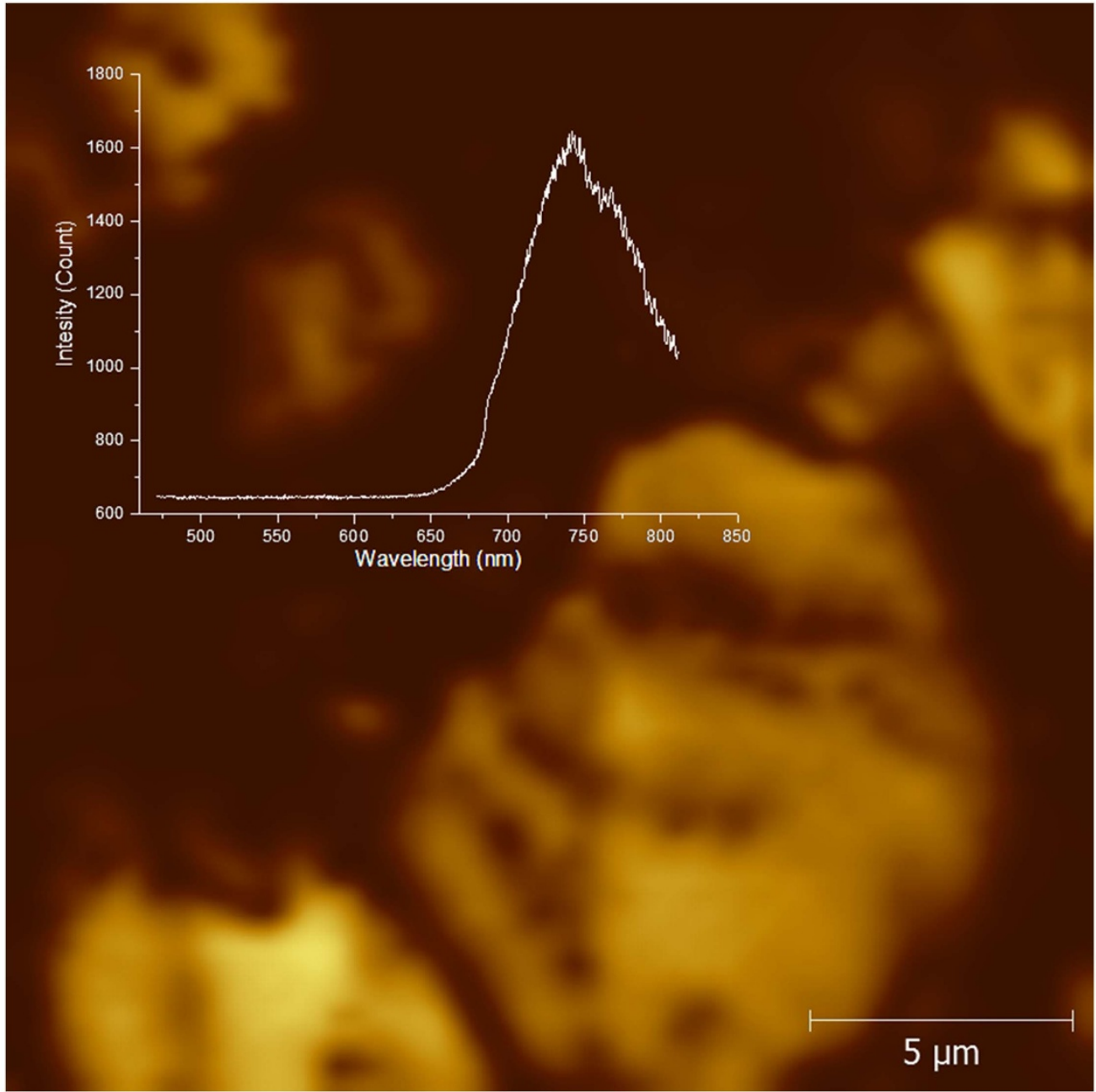

Figure 6 The map of photoluminescence distribution and its spectrum (see the inset) in the region shown in Figure 5. 
1. Maestre, D. et al. Structural and optoelectronical characterization of Si- $-\mathrm{SiO}_{2} / \mathrm{SiO}_{2}$ multilayers with applications in all Si tandem solar cells. J. Appl. Phys. 107, 064321-5 (2010).

2. Emel'yanenko, V. V. et al. Astronomical and Physical Aspects of the Chelyabinsk Event. Solar System Research 47, 240-254 (2013).

3. Grigoryan, S. S., Ibodov, F. S. \& Ibadov, S. I. Physical Mechanism of Chelyabinsk Superbolide Explosion. Solar System Research 47, 268-274 (2013).

4. Weber, I., Semenenko, V. P., Stephan, T. \& Jessberger, E. K. TEM studies and the shock history of a "mysterite" inclusion. Meteoritics \& Planetary Science 41, 571-580 (2006).

5. Brearley, A. J. \& Jones, R. H. Chondritic meteorites. In Planetary Materials (ed. Papike, J. J. ) Mineralogical Society of America, Washington, DC. 3-1-3-398 (1998).

6. Zucolotto, M. E. et al. Lavras do Sul: A New Equilibrated Ordinary L5 Chondrite from Rio Grande do Sul, Brazil. Earth Moon Planets 108, 139-150 (2012).

7. Motoyama, T. \& Matsumoto, T. The crystal structures and the cation distributions of $\mathrm{Mg}$ and Fe of natural olivines. Mineralogical Journal (Japan) 14, 338-350 (1989).

8. Kantor, I. et al. Pressure-induced phase transition in $\mathrm{Mg}_{0.8} \mathrm{Fe}_{0.2} \mathrm{O}$ ferropericlase Physics and Chemistry of Minerals (German) 33, 35-44 (2006).

\section{Acknowledgments}

We express our gratitude for providing us with the fragment of the Chelyabinsk meteorite to Researcher of the South Ural State University A.V. Gorshkov and Professor of Lobachevsky State University of Nizhni Novgorod I.V. Grebenev.

\section{Author contributions}

All authors contributed equally to this work. The study was conceived and guided by D.A.P. Preparation of the cross section of the meteorite fragment was carried out by D.A.P. and N.V.M. The investigation of the structure and chemical composition of the meteorite on the transmission electron microscope equipped with energy dispersive X-ray detector was made by A.I.B. and A.V.P. The measurements of combination scattering of light and photoluminescence spectra were performed by A.V.N. All the authors discussed the results and commented on the manuscript. A.I.B., A.V.P. and D.A.P wrote the paper.

\section{Additional information}

Competing financial interests: The authors declare no competing financial interests.

How to cite this article: Pavlov, D.A., Bobrov, A.I., Malekhonova, N.V., Pirogov, A.V. \& Nezhdanov, A.V. Self-assembled nanocrystals discovered in Chelyabinsk meteorite. Sci. Rep. 4, 4280; DOI:10.1038/srep04280 (2014).

This work is licensed under a Creative Commons AttributionNonCommercial-NoDerivs 3.0 Unported license. To view a copy of this license, visit http://creativecommons.org/licenses/by-nc-nd/3.0 